\title{
Historical Roots of International Biomedical and Health Informatics: The Road to IFIP-TC4 and IMIA through Cybernetic Medicine and the Elsinore Meetings
}

\author{
C. A. Kulikowski \\ Department of Computer Science, Rutgers University, USA
}

\begin{abstract}
Summary
Background: It is 50 years since the International Federation of Information Processing (IFIP) Societies approved the formation of a new Technical Committee (TC) 4 on Medical Information Processing under the leadership of Professor Francois Grémy, which was the direct precursor of the International Medical Informatics Association (IMIA).

Objectives: The goals of this paper are to give a very brief overview of early international developments leading to informatics in medicine, with the origins of the applications of computers to medicine in the USA and Europe, and two meetings - of the International Society of Cybernetic Medicine, and the Elsinore Meetings on Hospital Information Systems - that took place in 1966. These set the stage for the formation of IFIP-TC4 the following year, with later sponsorship of the first MEDINFO in 1974, setting the path for the evolution to IMIA.

Methods: This paper reviews and analyzes some of the earliest research and publications, together with two critical contrasting meetings in 1966 involving international activities in what evolved into biomedical and health informatics in terms of their probable influence on the formation of IFIP-TC4. Conclusion: The formation of IFIP-TC 4 in 1967 by Francois Grémy arose out of his concerns for merging, at an international level, the diverse strands from the more abstract work on cybernetic medicine and its basis in biophysical and neural modeling, with the more concrete and health-oriented medical information processing that was developing at the time for hospitals and clinical decision-making.
\end{abstract}

\section{Keywords}

International Biomedical and Health Informatics, IFIP-TC4, History, Cybernetic Medicine, Elsinore Meetings, IMIA, François Grémy

Yearb Med Inform 2017:257-62

http://dx.doi.org/10.15265//Y-2017-001

Published online May 8, 2017

\section{Introduction}

This paper gives a brief overview of how international activities in biomedical and health informatics started and evolved after World War II, together with a brief account of literature focusing on the history of the field in its precursor period before the formation of the International Federation of Information Processing Technical Committee 4 (IFIP-TC4) which was the predecessor of the International Medical Informatics Association (IMIA). IFIP-TC4 came about primarily as the result of the initiative of François Grémy [1, 2]. It was driven by antecedent work from computers in medicine, especially related to diagnostic logic and probabilistic reasoning and health care $[2,3,4,5,6,7,8,9,10,11,12,13,14]$, and more general approaches to computation in biology and medicine $[15,16]$, as well as the attempts to model the processes of communication and control under the rubric of cybernetic medicine [17], following the work of Wiener [18], and related to the information theory of Shannon [19]. This involved mathematical approaches taken by researchers from biophysics, bioengineering, epidemiology, biometry, and clinical documentation, together with clinicians who experimented with formal models of medical decision-making with various logical and statistical approaches, starting in the 1950's.

In 1958, an International Society of Cybernetic Medicine was founded, drawing on a wide range of researchers in math- ematics and physics, who worked with biologists and physicians. It started its own series of Cybernetic Medicine Congresses in 1960 in Naples [17]. In 1962, Gustav Wagner in Germany founded the journal Methods of Information in Medicine (MIM), which was the first journal oriented towards documentation and medical statistics [20], as well as information processing in the broadest sense of medical work, and which later became the official journal of IMIA. Figure 1 illustrates the cover of the first issue of MIM, with a part of its index.

The first fully medical-oriented international meeting of pioneering investigators working on computer data processing methods for hospitals and medicine more generally was held in Elsinore in 1966 [21].

These first steps toward an international organization led, over the next decade, to the first World Conference on Medical Informatics (MEDINFO) in Stockholm in 1974 [22], and the change in emphasis and designation from cybernetics and medical computer or electronic data processing, to the naming of medical informatics as a major professional endeavor with its broader emphasis on the full spectrum of biomedical and healthcare information. This led to a distinct discipline in the 1970's, foreshadowing the worldwide acceptance of the term informatics as defining the core of the new discipline in the 1980 's, and the universal adoption of this designation for all biomedical and health information-related work by the start of the new millennium. 


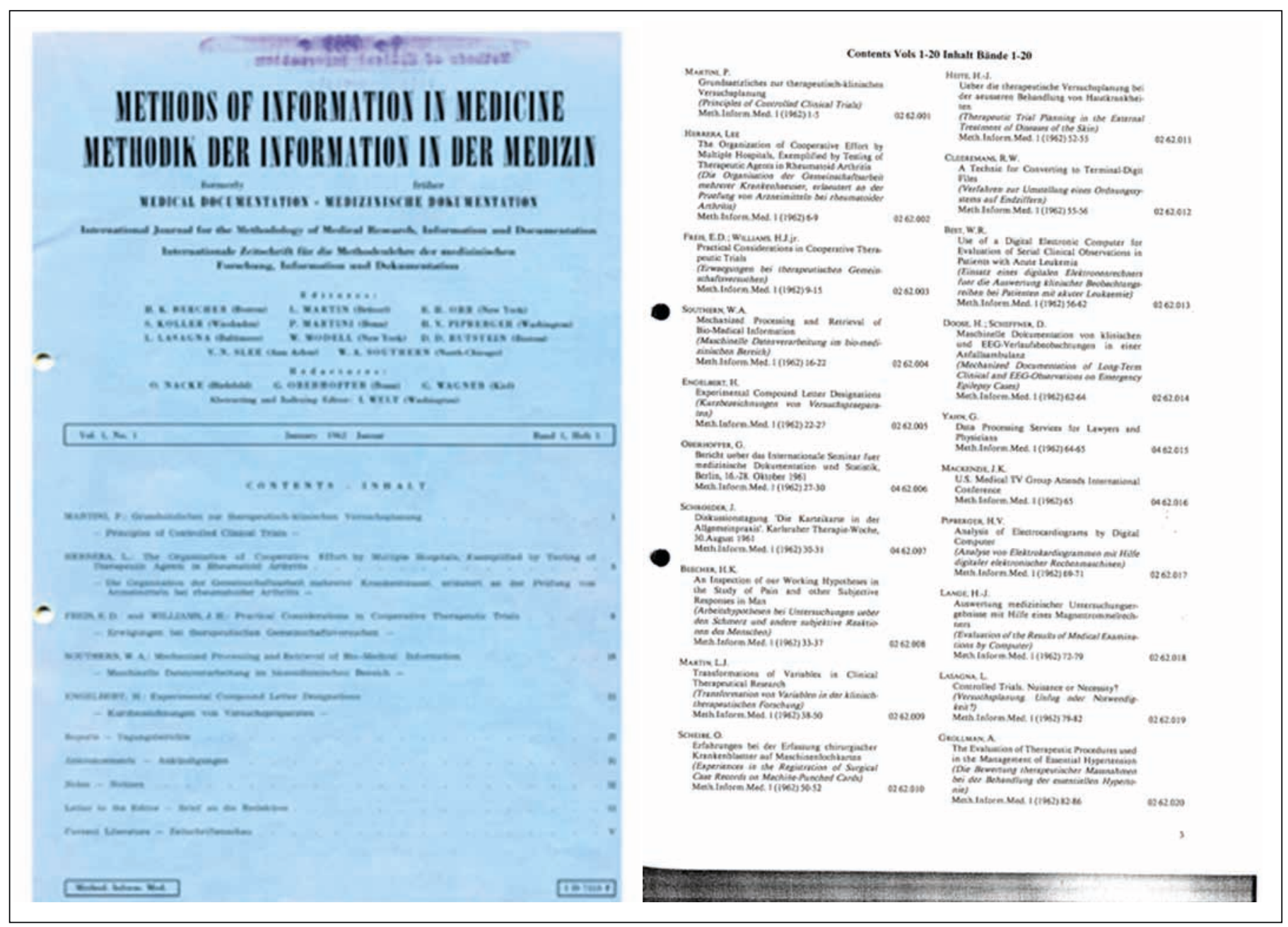

Fig. 1 Cover and part of the index of the first volume of the journal Methods of Information in Medicine, founded by Gustav Wagner in 1962.

\section{Early International Activities of Computers in Biology and Medicine: Cybernetics and Medical Information Processing}

In many countries, primarily in the USA and Europe, after World War II, several distinct scientific, engineering, and philosophical lines of mathematical research and its application to practical computer-related work, were developed at the interfaces of biology, medicine, and computer and communication technology. These were largely inspired by the cybernetics approaches pioneered by Norbert Weiner at MIT during the war [18], connected later to the work on syntactical information theory by Shannon at Bell Labs [19], dealing with the efficiency of signal transmission or electronic communication across noisy channels. This in turn attracted the attention of scientists and technologists who saw links to general human reasoning mechanisms related to the McCulloch-Pitts models of neuronal transmission [23]. They developed computer-based implementations of mathematical models for information coding, communication and control, as well as statistical models for signal processing - detection, classification, and prediction - which in turn gave rise to pattern classification and recognition methods in the 1960's [24, 25].

In Europe, Weiner's and Shannon's ideas were generally designated as cybernetics fol- lowing the popularity of the book of the same name [18], and when applied to medicine, this led to the First Congress on Cybernetic Medicine, organized by Aldo Masturzo in Naples in 1960, followed by another in Amsterdam in 1962, and a re-visit to Naples in 1964 [17]. However, it is the $4^{\text {th }}$ Congress held in Nice in 1966 [26] that likely had the greatest influence on the eventual emergence of medical informatics, since it was attended by Francois Grémy and his colleague JC Pagès, who could not have but helped observe the contrast between the very general and theoretical concerns with learning that was the focus of much of the work presented on cybernetics, as opposed to the more concrete applications of statistics and logic to medical diagnosis, which François Grémy summarized at the Nice meeting. 
In Germany, there was a strong tradition of medical documentation and analysis, which viewed information as central to medical recording, statistics, and organization processes [20], and led to the founding of Methods of Information in Medicine. Wagner's decision to start the journal came from his participation in the post-war German research on medical documentation (both paper and early computer-based) with its own professional society, the German Society for Medical Documentation and Statistics (GMDS.) Around this time, the documentation focus was reinforced by the consolidation of medical biometry and epidemiology research into academic departments. GMDS incorporated the work on medical documentation on which biometrical and epidemiological analyses were based, and was later re-named the Deutsche Gesellschaft für Medizinische Informatik, Biometrie und Epidemiologie while maintaining its GMDS abbreviation.

In the USA, which led the post-war world in the development of computer technology, science, and their applications, a most insightful physician and engineer, Dr. Morris Collen, who had worked on maintaining the health of workers at the Kaiser Industries that produced the Liberty Ships in Oakland, California, developed the systematic documentation of health conditions on cards, demonstrating the essential role of careful records in managing medical problems, as well as helping prevent future health problems through the multiphasic screening process he pioneered [8].

It was from all the above roots, that we can trace the emphasis on the centrality of information in supporting medical and healthcare practice tasks, which contrasted with the different and more abstract emphases that arose from the mathematical modeling and simulation research by biophysicists and bioengineers, and the statistical epidemiological investigations, and methodological researches in medical statistics which dated back to the $19^{\text {th }}$ and earlier part of the $20^{\text {th }}$ century before the advent of computers. All these strands of research caught the attention of the National Institutes of Health (NIH) in the USA, which set up an advisory committee under the leadership of Bruce Waxman in 1961 [27], leading to the emergence of ad-hoc study sections to evaluate grants for funding the field in the decade of the 1960's. In Japan, one of the other early computer adopting countries, work began also in the 1960's on medical electronic documentation, as well as on computational modeling for scientific inquiry and technological instrumentation.

In the late 1940's, strands of technology-oriented research had gradually arisen that was aimed at what is now usually known as decision-support for medicine. Robert Ledley, a dentist who joined the National Institute of Standards in the US stands out during this period for his remarkable insights, proposals, and actual system implementations showing how emerging computational technologies could assist not only medicine and dentistry, but all the healthcare disciplines and their underlying biomedical sciences [16]. He pioneered the formalization of medical diagnostic reasoning as statistical decision-making using Bayes/Laplace's Rule, and, joining with Dr. Lee Lusted, wrote the break-through paper in Science in 1959 [6] which brought formal statistical approaches for modeling medical decision-making to world-wide attention and encouraged a strong thread of research on the topic that persists in various formulations to this very day. Earlier in the 1950's, Nash [3] had experimented with a slide-rule model for capturing the logic of diagnostic combinations of signs and symptoms that could be aligned to "read out" a diagnostic category by an ingenious spatial placement of the slides to align with a plausible diagnostic category. A more wide-ranging set of approaches to the use of computers in support of clinical practice had been carried out, and encouraged, by Dr. Ralph Engle of Columbia University [11] who had worked with researchers at IBM Yorktown Height's TJ Watson Research Center. The series of IBM Medical Symposia lasted over a decade and examined various computational methods and systems. That "the time had come" to focus on medical diagnosis as a major scientific and practical problem was emphasized by John Jacquez's organization of The Diagnostic Process conference at Ann Arbor in 1961 [13], which further strengthened the idea that statistical decision-making was the major "way to go" in formalizing clinical as well as epidemiological reasoning. Around the same time, the Collen and Garfield group at Kaiser Permanente [8], building on the earlier work on preventive and occupational medicine, had developed a large database of cases from which they derived the frequencies of occurrence of various health problems under different conditions, which eventually led to one of the most systematic statistical likelihood ratio approaches to estimating risk of disease and other health-adverse conditions [28]. Collen's emphasis on preventive medicine, the efficiency of documentation and the analysis of intervention outcomes, had led to many statistical screening methods, such as the Cornell Index [29].

\section{The 1966 Elsinore Meetings - The First International Symposia for Medical Information Processing}

With the benefit of hindsight, it can be seen how, by 1966, the time was ripe for a truly medically-oriented international conference on the use of computers in the practice of medicine. The international meetings held in Elsinore, Denmark, in the shadow of the castle of Hamlet fame, were held in two parts from April 22 to May 3, 1966. They brought together many researchers and investigators from Europe, North America, and Japan, to discuss a range of diverse topics such as hospital and clinical computer systems, mathematical and statistical modeling and analysis of biomedical problems, cardiology, and laboratory data. Many of the participants contributed papers to the proceedings [21]. While the Proceedings title is "Automated Data Processing in Hospitals", the meetings comprised two separate programs, with the first one from April 20 to April 23, focusing on the hospital data processing theme and subtitled "An International Conference on the Interface Problems", while the second 
one running from April 25 to May 3 was more general, and entitled "International Advanced Symposium on Data Processing in Medicine".

The meetings were organized and chaired by Dr. A. Tybjaerg Hansen of Denmark, who gave a first address on "The role of computers in the hospital - the interface problems in medical and administrative patient management", thus highlighting a challenge which has persisted and endures to this day on the often conflicting electronic data processing (EDP) goals and the requirements for clinical or health care management purposes vs. administrative, financial, insurance, and hospital logistics purposes. Already in 1966, it was clear that different data and interfaces were required for the very different clinical vs. administrative processes, as discussed by many participants following Dr. Hansen's presentation, such as Charles Flagle of Johns Hopkins who gave an operations research perspective on the requirements for information systems in hospitals, Homer Warner of the University of Utah who presented computer time-sharing for processing patient data from the bedside (reflecting his pioneering work on cardiology in the ICU), and Henry Yellowlees from the United Kingdom who talked about the computer in the National Health Service.

Analog-Digital Data Processing, which was still a major concern for interfacing instrumentation and interpreting their analog signals, was emphasized by Dr. Antoine Remond from Pitié - Salpétrière Hospital in Paris, and Josiah Macy, Jr, from Yeshiva University in New York, who talked about "Hybrid Systems for a Hybrid World" during the second day of the meeting. Specific instances were then given by the Drs. Caceres, Pipberger, and Adey who described their work on the analysis of ECGs, and by Dr. Weil for the management of the critically ill. The third day covered computers in clinical laboratory, radiation planning, and the diagnosis of congenital heart disease and brain tumors with speakers from the USA, Sweden, the Netherlands, and Japan. There was also a discussion on Man-Machine Communication in the Hospital by Octo Barnett, the pioneer from Massachussetts General Hospital and Harvard, concluded by Gustav Wagner, from Heidelberg, with a talk on The Information Problem in Medicine, though his written contribution was on Quality Control in Medicine. The last day of the first set of meetings was devoted to hospital information issues.

The second part of the Elsinore meetings covered seven themes: computer-assisted processing of biomedical information, cybernetics in medicine, computers in patient management and the use of operations research methods, analog information, man-machine communication in the hospital, education in computers, and instruction in automated data processing (ADP) for hospital personnel. The first day was chaired by Dr. Remond and featured a questioning of the aims of data processing in medicine by E. Dessau of Copenhagen, with talks by Dr. Donald A.B. Lindberg of the University of Missouri on "Processing and Evaluation of Hospital Laboratory Data", by Dr. Homer Warner on "The Digital Computer as Tool for the Analysis of Physiological Systems", and concluded by Dr. Hansen speaking about "Clinician's Wishes and Expectations about Data Processing". The next day covered hybrid systems and intensive observation and care units with many of the speakers of the first set of meetings, while it was followed by one on Analog Data Acquisition and Processing which ended with a demonstration of the then-novel online time-sharing service between Elsinore and the Systems Development Corporation (SDC) in Santa Monica, California by Dr. Anne Summerfield. All these presentations were very concretely based on working clinical systems and the experience of clinicians with their operation.

\section{The 1966 International Congress of Cybernetic Medicine in Nice: A Study in Contrasts}

The Fourth Cybernetic Medicine Congress held in Nice from the $19^{\text {th }}$ to the $22^{\text {nd }}$ of September of 1966 was, like the Elsinore meetings, divided into two very different segments, denoted as subjects or themes.
The first subject of the Cybernetic Medicine meeting in Nice was "Devices of Command and Control in Learning", which had three parts -"Learning Processes in Machines", "Brain Mechanisms of Learning Communications", and "Man-Machine Interrelationship from the Point of View of Learning". The first two parts reflected the early and immature stage of knowledge about learning by machines, such as using simple perceptrons or feed-forward linear artificial neural networks that had not yet been sufficiently understood in terms of their limitations [30], as effective mathematical models for learning concepts or hypotheses from evidence. This was mixed with much conjectural discussion about putative models of biological learning in the brain, the role of esthetics, and "molecular memory", all treated at a most superficial level reflecting the poor understanding of neural mechanisms of the period. The third part on Man-Machine Inter-relationships for learning was very concrete, featuring specific examples of computer teaching machines, discussing the use of the then-ubiquitous microfilm, electronic calculators, and very basic computers for instruction, as well as a discussion of misunderstandings based on Weizenbaum's deliberately ironic simulation of a Rogerian psychiatric interaction through the chatbot ELIZA [31]. However, the papers were almost all about generic computer processing, and non-specific to medicine despite the title of the conference.

The second subject of the conference, however, did cover a wide range of topics about collecting and processing medical data, starting with the basics of computer representation of numbers and text, with medical examples from general statistical diagnosis, electrocardiogram interpretation, automating documentation in medicine, the automation of medical records using mark-sense documents, and several cardiovascular modeling and simulation methods as well as psychiatric models. This part of the conference was medically oriented, but it is almost impossible to see connections with the first part on cybernetics and learning. In this sense, the conference would have split the audience in two: those interested in the abstract issues of 
learning, and those interested in practical medical applications of computing. While this may have been a reasonable strategy at the time, given the primitive state-of-the art in cybernetics, one cannot but feel that it must have left the medical audience, and their presenters, like Francois Grémy, with little doubt that any real impact on medicine by cybernetics would remain far in the future.

The contrast in the split at the Nice meeting between the conjectural cybernetics learning discussions and the practical clinically-oriented discussions that Grémy and Pagès experienced during their attendance at the Elsinore meetings might have impressed them greatly - it was at Elsinore that there had been so many specific, concrete, examples presented that bridged hospital, laboratory, and clinical applications of computers with the practice of healthcare. The highlighting of so many of these technologically-grounded projects would have likely reinforced what Grémy had experienced during a visit to MIT two years earlier [32].

\section{Conclusion: The}

\section{formation of IFIP-TC 4 and the First World Conference on Medical Informatics - MEDINFO 1974 in Stockholm, Sweden}

In 1967, Professor Francois Grémy formed the Technical Committee 4 (TC4) in Medical Information Processing within the International Federation for Information Processing (IFIP). He had already, during the Fourth Congress on Cybernetic Medicine held in Nice in September 1966, emphasized the historical importance of "informatique" and the "reasons" for a marriage between medicine and informatics [2]. As mentioned above, Grémy and Pagès had attended the highly contrasting presentations at the Nice Congress, and may have realized how important it would be to emphasize concrete medical applications of computers to move the field forward, rather than the extremely conjectural and abstract topics of learning in humans and machines that characterized the direction of cybernetics at the time. The success of the Elsinore meetings in dealing with practical issues of information processing for hospitals and clinical tasks and the more specific advances of statistical, especially Bayesian, methods for modeling medical decision-making likewise drew Grémy's attention, as his talk in Nice summarized developments of statistical methods for diagnosis [2]. Such observations most likely motivated him to consider the formation of a professional organization to advance a more synthetic discipline bridging the practical work on medical information processing combined with the mathematical modeling for measurable biological systems and the statistical modeling for decision-making, while putting aside for the longer term the automated learning aspirations of cybernetics. From the perspective of 50 years later, where we are still struggling to understand learning, this turned out to be a wise decision. Patrice Degoulet, who met and talked with Grémy for the first time around 1970, recalls that the factors that plausibly influenced Grémy's decision to form TC4 included: a) the truly international nature of IFIP, 2) the federated nature of IFIP's organization with specific technical committees - subsequently inspiring IMIA's mode of organization, 3) the strong link of IFIP with UNESCO - the "biological father "of IFIP, and 4) the fact that IFIP agreed to create IFIP TC4 under the leadership of François Grémy with Forsythe as Secretary [33].

The first meeting of the TC4 was held in Paris in April 1968, with a dozen nations represented and Grémy as president. During the following years, he was instrumental in the development and formation of several working groups covering various subfields of medical information processing. In 1969, Grémy founded the INSERM Unit U88 entitled Informatics and Statistics Methodology in Medicine as an environment in which close collaborators developed informatics, statistics, and decision support systems in medicine. Grémy used TC4 as the vehicle to organize

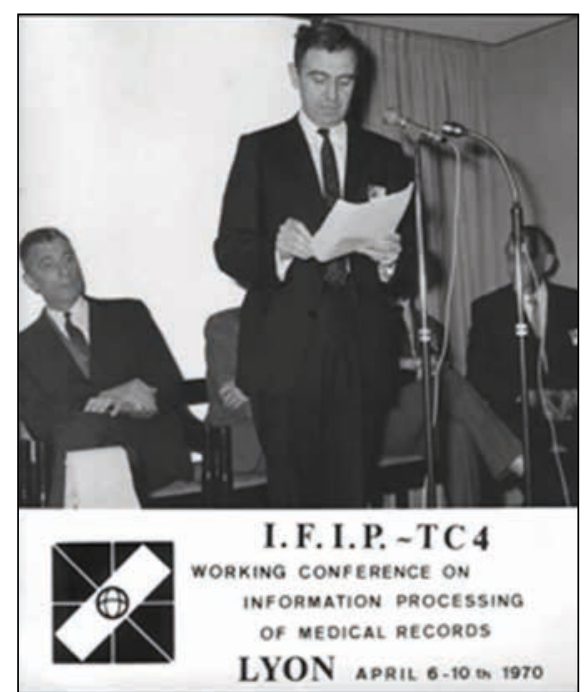

Fig. 2 Francois Grémy addressing the IFIP-TC 4 Conference held in Lyon in 1970.

many meetings $[34,35]$ like the one on information processing in medical records [36] held in Lyon in 1970 illustrated in the picture displayed as Figure 2.

Other IFIP-TC 4 meetings were held in the following years on the topics of signal processing, mathematical models in biology and medicine [37], education informatics for healthcare personnel with J Anderson and JC Pagès [38], and decision support with FT de Dombal [39].

The first MEDINFO, organized by IFIP-TC4, was held in 1974 in Stockholm concurrently with the IFIP meeting from August 5th to $10^{\text {th }}$ [22]. François Grémy was chair of the Program Committee, while J. Anderson and J.M. Forsythe were editorial committee co-chairs. Grémy had negotiated with the IFIP leadership a separate conference dedicated to healthcare data processing, and this was accepted since there was great hope at that time that computers in medicine would help not only improve healthcare but also lead to dramatic new discoveries in biomedicine - like a cure for cancer. As a result, the seeds for the evolution of IFIP-TC4 into IMIA were sown by this transition at MEDINFO 1974 towards a focus on practical computer models and methods for information processing in biomedicine and health care more generally, which later became the central concern of IMIA - which now gets ready to celebrate its $50^{\text {th }}$ Birthday. 


\section{Acknowledgments}

I would like to thank my many friends and colleagues, and especially the members of the IMIA History Working Group, and of the American College of Medical Informatics (ACMI) Committee of Historians for their suggestions, support, and help in starting and pursuing the projects related to the history of biomedical and health informatics. I would also like to thank the reviewers and editors of the IMIA Yearbook for their valuable and untiring help and suggestions.

\section{References}

1. Grémy F, Leterrier F. Eléments de biophysique. Tome 1. Paris: Flammarion Médecine-Sciences; 1966.

2. Grémy F, Joly H, Pages J-C. Application des Machines à Traiter l'Information au Diagnostic Médical. In Proceedings IVth Congres International de Médecine Cybernetique (Masturzo A, Nayrac P, eds), Nice, France, September 1966. p. 289-97.

3. Nash FA. Differential Diagnosis, an apparatus to assist the logical faculties. Lancet 1954;266:874-5.

4. Paycha F. Critique scientifique des démarches intellectuelles du diagnostic. Presse Med 1955; 63:1753-6.

5. Lipkin M, Hardy JD. Mechanical correlation of data in differential diagnosis of hematological diseases. JAMA 1958; 166: 113-25.

6. Ledley RS, Lusted LB. Reasoning Foundations of Medical Diagnosis Science. 1959;130:9-21.

7. Overall JE, Williams CM. Models for medical diagnosis. Behav Sci 1961;6:134-41.

8. Collen MF, Rubin L, Neyman J, Dantzig GB, Baer RM, Siegelaub AB. Automated multiphasic screening and diagnosis. Amer J Public Health 1964;54:741-50.

9. Warner HR, Toronto AF, Veasy LG, Stephenson R. A mathematical approach to medical diagnosis. Application to congenital heart disease. JAMA 1961;177:177-83.
10. Feinstein AR. Boolean algebra and clinical taxonomy. I. Analytical synthesis of the general spectrum of a human disease. New Eng J Med 1963;269:929-38.

11. Engle RL, Davis BJ. Medical Diagnosis: Past, Present and Future: III: Diagnosis in the future, including a critique on the use of electronic computers as diagnostic aids to the clinician. Arch Int Med 1963;112:530-43.

12. Jacquez JA. The Diagnostic Process: Proceedings of a Conference at the University of Michigan; 1963.

13. Lusted LB. Introduction to Medical Decision Making. Springfield, IL: Charles C. Thomas; 1968.

14. Lindberg DAB. The Computer and Medical Care. Springfield, IL: Charles C. Thomas; 1968

15. Enslein K, editor. Data Acquisition and Processing in Biology and Medicine. New York: Pergamon; 1964.

16. Ledley RS. Use of Computers in Biology and Medicine. New York: McGraw Hill; 1965.

17. Masturzo A. Cybernetic Medicine. Springfield IL: Charles C Thomas; 1965.

18. Weiner N. Cybernetics or Control and Communication in the Animal and the Machine. New York: MIT Press and J Wiley; 1948.

19. Shannon CE. A Mathematical Theory of Communication. Bell System Technical Journal 1948;27:379-442 and 27:623-56, and Shannon CE, Weaver W. The Mathematical Theory of Communication. Urbana IL: Univ of Illinois Press; 1949.

20. Oberhoffer G. Report on an international seminar for medical documentation and statistics. Methods Inf Med 1962;1:27-31.

21. Hansen T. Proceedings of the First International Hospital Data Processing Conference, Elsinore; 1966.

22. Proceedings of the First International Conference on Medical Informatics, Stockholm. North-Holland; 1974

23. McCulloch WS, Pitts WA. Logical Calculus of Ideas Immanent in Nervous Activity. Bulletin of Mathematical Biophysics; 1943;5:115-33.

24. Uhr L. Pattern Recognition Psychol Bulletin 1963;60:40-73.

25. Watanabe S. Knowing and Guessing, New York: Wiley; 1968

26. Masturzo A, Nayrac P, editors. Proceedings IVth Congres International de Medecine Cybernetique. Nice, France: Editions C.R.E.N.A.F.; September 1966.
27. Waxman BD. Public Health Service support of biomedical computing. Proceedings 3rd IBM Medical Symposium, Endicott, NY IBM; 1961:199-202.

28. Collen M. Automated multiphasic screening as a diagnostic method for preventive medicine. Methods Inf Med 1965;4:71-4.

29. Brodman K, van Woerkom AJ. Computer-aided diagnostic screening for 100 common diseases. JAMA 1966;197:901-5.

30. Minsky M. Perceptrons. MIT Press; 1968.

31. Weizenbaum J. Computer Power and Human Reason: From Judgment to Calculation. New York: W.H. Freeman and Company; 1976.

32. Grémy I. Personal Communication from JC Pagès transmitted by B Séroussi.

33. Degoulet P. Personal Communication via B. Séroussi.

34. Degoulet P, Haux R, Kulikowski C, Lun KC. François Grémy and the Births of IMIA. 1st IMIA/ UMIT Medical Informatics Award of Excellence given to Professor Grémy. Methods Inf Med 2005;44:349-51.

35. Degoulet P, Fieschi M, Goldberg M, Salomon R. Francois Grémy, a Humanist and Information Sciences Pioneer. Yearb Med Inform 2014;9(1):3-5.

36. Anderson J, Forsythe JM, editors. Information Processing of Medical Records. Proc of the IFIP-TC4 Working Conference on Information Processing of Medical Records, Lyon, April 6-10, 1970. Amsterdam: North-Holland; 1970.

37. Zywietz C, Schneider B, editors. Computer Application on ECG and VCG Analysis. Proc 2nd IFIP-TC4 Working Conference, Hanover 1971. Amsterdam: North-Holland; 1973.

38. Anderson J, Grémy F, Pagès JC, editors. Education in Informatics of Health Personnel. Amsterdam: North-Holland; 1974.

39. De Dombal FT, Grémy F, editors. Decision Making and Medical Care. Amsterdam: North-Holland; 1976.

\section{Correspondence to:}

Casimir A. Kulikowski

Department of Computer Science

Rutgers - The State University of New Jersey

Piscataway, New Jersey, USA

E-mail: kulikows@cs.rutgers.edu 